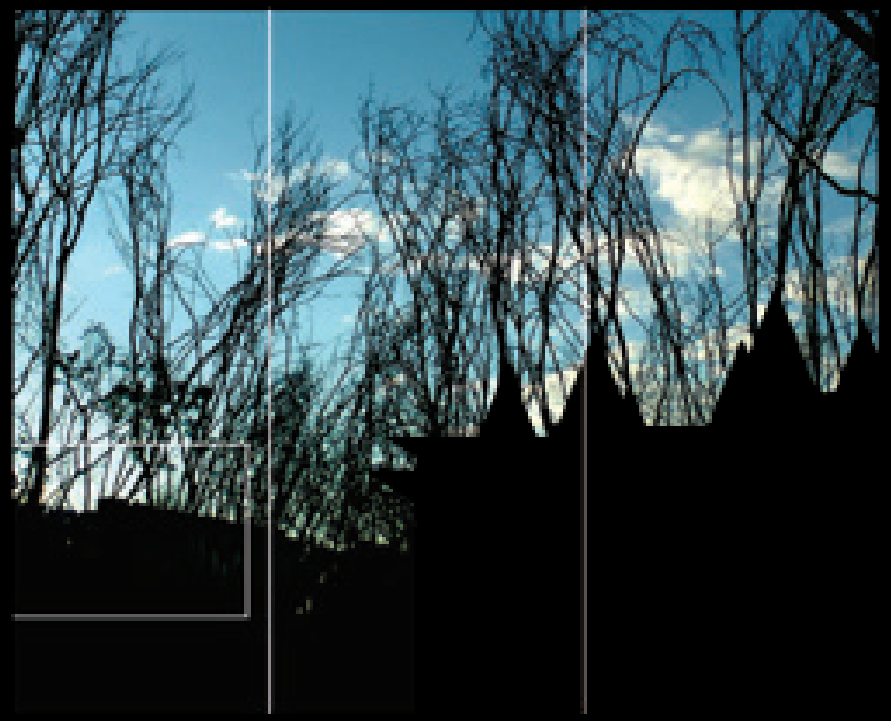




\section{Hospitalidade urbana e design de espaços públicos: a trajetória da Praça Almirante Tamandaré em Balneário Camboriú/SC. Brasil}

Urban hospitality and the public space design: the path of Almirante Tamandaré Square in Balneário Camboriú/SC. Brasil

Heron de Sousa Arruda ${ }^{1}$ Luciano Torres Tricárico²

1 Professor de Arquitetura e Urbanismo, Engenharia e Design de Interiores. Pós-graduado em Programa de mestrado em Gestão de Políticas Públicas. Mestrando em Turismo e Hotelaria.

2 Professor do Programa de Mestrado em Turismo e Hotelaria da UNIVALI. Graduado em Arquitetura e Urbanismo pela Universidade Estadual Paulista Júlio de Mesquita Filho, Mestre em Arquitetura e Urbanismo pela Universidade de São Paulo e Doutor em Arquitetura e Urbanismo pela Universidade de São Paulo. 


\title{
Resumo
}

Esta pesquisa objetiva resgatar a história da Praça Pública Almirante Tamandaré em Balneário Camboriú/SC, evidenciando sua importância para a cidade e para o turismo, pela posição privilegiada, por ser um espaço multifuncional e, sobretudo pela sua história impar, descrita por vários atores da gestão pública de Balneário Camboriú. No contexto desta história da Praça Tamandaré, pretende-se explicitar a relação da hospitalidade urbana e o design de espaço público e a e sua implicação no turismo da cidade. Com relação à metodologia, a pesquisa será qualitativa, exploratória, com caráter fonomenológico, aliado ao uso da história oral como método para coleta de entrevistas, além de pesquisa documental em arquivos históricos e bibliografia de autores contemporâneos que pesquisam na área de turismo. Entre os resultados revelou-se que a atividade turística prescinde dos espaços públicos das praças da área central de Balneário Camboriú, da forma como se apresentam atualmente.

Palavras-chave: Turismo. Hospitalidade Urbana. Praças Públicas.

\begin{abstract}
This research aims to rescue the history of Almirante Tamandaré public square in Balneário Camboriú/SC, evidencing its importance to the city and to the tourism, considering its privileged position and that it is a multifunctional space and, above all, its unique history, described by several actors of public management and citizens that live in Balneário Camboriú city. In the context of the Tamandaré Square's history, the research intends to make explicit the relation between the urban hospitality and the public space design, as well as the consequent implications on the tourism of the city. Concerning to the methodology, the research will be qualitative, exploratory, of phenomenological character allied to oral history as the method used to collect interviews, besides documentary research in historical files and bibliographies of contemporary authors. Among the results proved that tourism dispenses public spaces of the squares of the central area of Balneario Camboriu, the way in which they currently have.
\end{abstract}

Keywords: Tourism. Hospitality. Public Squares.

\section{INTRODUÇÃO}

Balneário Camboriú se destaca no cenário turístico nacional como um destino turístico consolidado, por ter condições excepcionais de balneabilidade nas suas praias, por um patrimônio paisagístico de grande importância e localização privilegiada pela proximidade dos grandes centros do sul do país (Florianópolis $83 \mathrm{~km}$, Curitiba 224 km e Porto Alegre 522 km). 
Em 1964 elevou-se à categoria de município emancipado da cidade de Camboriú, tornando-se rapidamente um destino turístico com infraestrutura para atender a demanda, e este crescimento veloz levou ao Primeiro Plano Urbanístico, cujos estudos se iniciaram no final dos anos 60, no mandato do primeiro Prefeito Municipal eleito, Higino João Pio e foi apresentado como Plano Diretor em 1974, na gestão do prefeito Gilberto Meirinho (MEMORIAL, 2014).

O projeto seguiu o modelo de desenho da época, modernista, inspirado no projeto de Curitiba - Plano Preliminar de Urbanismo para Curitiba, dos escritórios Jorge Wilheim - Arquitetos Associados e Sociedade Serete de Estudos e projetos Ltda. Os desenhos urbanos da época sofreram influência da escola racionalista da Europa (NERY, 2013) cuja reorganização criou grande repercussão e muitos adeptos das soluções "técnicas" de problemas urbanos, como menciona Marcelo Lopez de Souza (2013, p.123), quando se refere ao planejamento físico-territorial, elaborado como uma tentativa de estabelecer uma "cidade ideal". A materialização do projeto carregava todo ideário modernista, a começar pelo master-plan, definindo a cidade na escala macro, com intenções de implantar uma nova realidade para o futuro da sociedade, a partir de mudanças na organização espacial.

A Praça Tamandaré originou-se na implantação do plano urbanístico referido acima, quando a obra da Avenida Atlântica, a avenida beira-mar que margeia quase todos os sete quilômetros da orla da praia principal, estava sendo executada ( MEMORIAL, 2014). Em uma situação paradoxal, onde a solução para um impedimento legal do traçado original da via acabou gerando um espaço público não planejado inicialmente, conforme se propõe apresentar neste trabalho, no capítulo "Praça Almirante Tamandaré".

Localizada no centro geográfico e geométrico da orla da baía, porém não só pela localização, mas por muitos aspectos este espaço se configura como privilegiado tanto pelo caráter multifuncional, como por exemplo: celebração de comemorações, manifestações e outros eventos artísticos, culturais, de lazer e de comércio, de produtos artesanais; e também por se constituir como referência e síntese da memória urbana, tornando-se então, uma parte importante da história da cidade.

Este artigo busca resgatar a história da praça e estudar a relação entre a hospitalidade pública e o design urbano que se evidencia na história deste espaço público. Estudos sobre hospitalidade relacionada com os espaços urbanos têm sido tema sobre o qual muitos autores têm se debruçado, apresentados com maior profusão nas últimas décadas, segundo Lúcio Grinover (2009, p.123), cujos textos abordam conceitos inovadores sobre a hospitalidade urbana, apontando para um entendi- 
mento mais amplo do que o simples acolhimento. A prática da hospitalidade estaria condicionada à infraestrutura existente, como patrimônio construído atraente.

A noção clássica de hospitalidade é questionada também no trabalho de Luiz Otávio de Lima Camargo (2009, p.2), onde ele se refere como "espaço desejável" de inserção na cidade na qual o visitante ou turista chega. Neste trabalho apresenta-se a fundamentação teórica que caracteriza estes espaços públicos das praças e a importância do projeto (design) para que a população local se aproprie destes lugares e que esta identificação proporcione a hospitalidade.

Parte-se do pressuposto de que este espaço público destinado ao lazer e ao turismo, a praça pública Almirante Tamandaré, não atende aos anseios da população local, tampouco serve adequadamente à atividade turística. Ou seja, podem existir problemas de hospitalidade urbana relacionados com o design inadequado da praça do centro da cidade.

Para entender a praça é necessário compreender o fenômeno urbano que se relaciona com os projetos que deram início ao sistema viário do balneário, e o Primeiro Plano Diretor Municipal, conforme contrato constante nos arquivos do Memorial Prefeito Meirinho (MEMORIAL, 2014). Este assunto será tratado no capítulo 3 "Contexto político e o Plano Diretor".

Quanto à relevância da pesquisa, pode-se dividir em dois aspectos, sendo o primeiro teórico e o segundo, o aspecto social que a pesquisa pretende interpor.

I - Relevância teórica: Propõe-se um avanço interdisciplinar na reflexão sobre o tema, tornando a abordagem ampla no sentido de proporcionar maior trânsito de conhecimentos, e verificar a relação entre design urbano e hospitalidade pública nos espaços públicos da cidade. Justifica-se também pelo ineditismo do tema, registrando uma história recente de espaço público em área de enorme importância turística. II - Relevância social: Resgate de parte importante da história da cidade e a manutenção de valores e crenças do imaginário social urbano com adequada interpretação dos conceitos de hospitalidade pública e design urbano.

Com relação à metodologia, a pesquisa será qualitativa, exploratória, com caráter fonomenológico, aliado ao uso da história oral como método para coleta de entrevistas. Será construída em duas etapas distintas: I. Parte documental e bibliográfica em fontes secundárias. II. Em campo: entrevistas com pessoas envolvidas com a história das praças de Balneário Camboriú: gestores das instituições públicas municipais.

O recorte temporal escolhido foi o período a partir da implantação do Plano Urbano de Balneário Camboriú SC, em 1974, quando da criação deste espaço público, até 2013 , com a última intervenção no design da praça. 
Entre os resultados revelou-se que a atividade turística prescinde dos espaços públicos das praças da área central de Balneário Camboriú, da forma como se apresentam atualmente.

\section{FUNDAMENTAÇÃO TEÓRICA}

$\mathrm{Na}$ antiguidade greco-romana, a praça era o espaço público de maior importância na cidade e funcionava como o espaço vital (ROLNIK, 1992 p.28). A Ágora desempenhava um papel preponderante: era o locus publicci da vida citadina, e ali se concretizava o conceito de cidadania. Já nas cidades contemporâneas, criam-se necessidades antes não observadas - de informação, simbolismo, de atividades lúdicas, de espaços de trocas ${ }^{3}$. $O$ ambiente criado no meio urbano se constrói de acordo com as expectativas, interesses e necessidades humanas, mas também se dá ao inverso: os espaços públicos determinam comportamentos, favorecem trocas, proporcionam oportunidades e realizam encontros, diálogos, ou seja, "um espaço público onde se pratica a hospitalidade". (GRINOVER, 2009, p.7).

As praças representam espaços de sociabilidade propícios ao convívio e ao encontro dentro do contexto da urbi. São símbolos, referências, reservas e vazios da malha urbana, funcionando como descompressão ao fornecerem ruptura na paisagem edificada.

Para entender a praça é necessário compreender a história da cidade, sua formação e antecedentes históricos, as demandas sociais e modelos adotados de urbanização que definiram e definem ainda sua morfologia, refletindo, em certa medida, uma forma de ocupação e apropriação do espaço próprio da cultura. Aldo Rossi (2009, p.13) refere-se à cidade como memória coletiva dos povos; e como a memória esta ligada a fatos e a lugares, a cidade é o locus da memória destes; "princípio característico dos atos urbanos". A memória coletiva se torna a própria transformação do espaço, e essa memória coletiva permite o entendimento da estrutura urbana e a sua relação com a coletividade.

Constantemente vemos a cidade se tornar uma mercadoria e o city marketing ${ }^{4}$

3 O conceito de Espaços de Trocas aqui utilizado, é amplamente discutido em "O Direito à Cidade", de Henri Lefebvre LEFEBVRE (1991).

4 City Marketing ( ou branding) é apromoção da cidade ou parte dela, com o objetivo de incrementar determinados eventos ou atividades e costuma ser utilizado para enaltecer as características de um lugar, atraindo turistas. A "marca" de uma cidade serviria como propulsor de comercialização dacidade como um produto. A autora Fernanda Sánchez em seu livro "A reinvenção das cidades" discorre longamente sobre o advento do city marketing e a emergencia de um mercado mundial de cidades, traçando um paralelo entre Curitiba no Brasil e Barcelona na Espanha, como sendo expressões emblemáticas das novas formatações urbanas. 
pode se opor à polis, o mercado subordina, às vezes elimina a ágora. Cidades-imagens têm muito mais relação com o mercado do que com a vida citadina onde temos cada vez menos cidadãos e cada vez mais acionistas da empresa cidade e os turistas tornam-se consumidores da cidade-mercadoria (SANCHEZ, 2002, p.49). Dentro deste contexto, a hospitalidade passa a ser refém dos investimentos em atratividade. Constroem-se atrações com intuito de angariar turistas para estes espaços edificados, mas que representam uma imposição para a população local. Criam-se cenários, cada vez mais e mais caros, destinados à visitação pública, para sustentar um nível de atratividade mantendo a estatística alta de clientela turística.

O que tem um efeito negativo é a "maquiagem" de alto custo de algumas cidades, que drenam a economia local, em detrimento dos investimentos básicos necessários para a qualidade de vida dos moradores. Por outro lado, as praças podem ser o lócus adequado para diminuir barreiras físicas e simbólicas dentro do contexto urbano. Na história do ocidente a praça pública foi sempre o lugar hospitaleiro por definição, reunia funções de convívio, comércio livre, manifestações de toda ordem e referência da cidade.

A praça é um logradouro do espaço turístico urbano, para Boullón (2002, p.189), que a conceitua como área nítida, relativamente pequena diante da superfície total de uma cidade, mas muito importante na formação da imagem turística da mesma. Fábio Robba e Silvio Soares Macedo (2010, prefácio) definem a praça como espaço livre urbano, destinado ao lazer e ao convívio da população, acessíveis aos cidadãos e livres de veículos.

A praça pode ser a versão atual da Ágora, onde a hospitalidade se realiza, também por ser um espaço livre e democrático e hoje alicerçado nos preceitos fundamentais da sustentabilidade. $O$ tema sustentabilidade é muito frequente nos artigos que tratam de espaços públicos urbanos. Por ser tão relevante em questões relacionadas com a qualidade de vida, ganham muito destaque e a praça pública se enquadra como um reduto da vida social saudável. Quando se propõe revitalização de centros de cidades, as praças deverão se tornar espaços privilegiados, tanto por serem multifuncionais, como por carregarem um conteúdo simbólico forte no imaginário coletivo.

A discussão conceitual encontrada na produção científica, relacionada com o tema aqui proposto, leva a considerar que, transportando os conceitos levantados para o objeto desta pesquisa, encontramos que o espaço estudado não corresponde exatamente à Ágora, por não comportar a característica de ponto de encontro, convergência ou manifestações sociais. Não é espaço de trocas ou um espaço público onde se pratica a hospitalidade, como foi sugerido por Lúcio Grinover (GRENOVER, p.127), mas se configura como um "vazio urbano", espaço não edificado e disponível na malha urbana, perdendo muito do seu caráter hospitaleiro. 
A Praça Almirante Tamandaré tem sido utilizada, desde a sua criação até a atualidade, como um espaço disponível para eventos, muito distante do que a população local se refere como o projeto ideal.

As entrevistas dos atores que participaram de alguma forma no processo de implantação do projeto da cidade demonstram que, apesar das constantes alterações na morfologia do lugar, a praça nunca esteve apropriada para estes moradores. Com a utilização do modelo de análise do Discurso do Sujeito Coletivo, DSC (Lefèvre e Lefèvre, 2000) foi detectada a ideia de praça pública idealizada pelos entrevistados, sendo recorrente a referencia aos jardins, playgrounds, quiosques, espaços para atividades físicas, bancos, serviços, e água (chafariz ou espelho d’água). Como a praça não oferece estes itens apontados como importantes para as pessoas, as expressões mais utilizadas foram "desconfortável" "não aconchegante" "sem equipamentos" e "sem atrativos". Os poucos que se referiram ao espaço disponível para eventos, utilizaram a palavra "necessário" ou a expressão "tem que ter algum lugar para este fim", demonstrando aceitação, com resignação da praça como um lugar vazio, para eventos apenas.

\section{CONTEXTO POLÍTICO E O PLANO DIRETOR}

Neste trabalho enseja-se relatar a história que se inicia com a implantação do Plano Urbano para a cidade de Balneário Camboriú, em 1974, cuja obra deu origem de maneira acidental, à Praça Almirante Tamandaré, segundo relato de alguns moradores que tiveram envolvimento com este projeto urbanístico.

No ano de 1973 o Brasil vivia sob o regime militar e o presidente vigente era o General Emílio Garrastazu Médici, cujo governo esteve entre os anos denominados de "anos de chumbo"5 (D’ARAUJO, et al 1994). O Programa de Governo se estruturava na execução do Primeiro Plano Nacional de Desenvolvimento (PND, 1973), que tinha por objetivo promover o crescimento econômico do País. Ainda alimentado pelo desenvolvimentismo ${ }^{6}$ que predominou nos governos militares no Brasil, o país captou muitos empréstimos no exterior e investiu em obras de grande porte em

5 A expressão passou a designar esse período de radicalização política, também fora da Europa - particularmente nos países do Cone Sul. Os Anos de Chumbo estão descritos no livro de mesmo nome de D'ARAUJO, M.C. SOARES, G.A.D. CASTRO, C. Rio de Janeiro: Relume-Dumará, 1994.

6 Desde os anos 1930 o Nacional Desenvolvimentismo exerceu uma forte influência ideológica e política nos principais debates da agenda nacional, até o seu ocaso nos anos $1990 \mathrm{com}$ a ascensão do neoliberalismo. O desenvolvimentismo é uma política de resultados, e foi aplicado essencialmente em sistemas econômicos capitalistas, como no Brasil (governo JK) e no governo militar, quando ocorreu o "milagre econômico brasileiro".O desenvolvimentismo foi uma resposta aos desafios e oportunidades criados pela Grande Depressão dos anos 30. Os projetos nacionais de desenvolvimento e industrialização na periferia nasceram no mesmo berço que produziu o keynesianismo nos países centrais. (Centro Celso Furtado). 
todo o território nacional. Destes investimentos públicos surgiu o que se chamou de Milagre Brasileiro (SINGER, 1972).

Durante este período circunstancial da vida brasileira instaurou-se um pensamento ufanista de "Brasil potência", que se evidenciou com a conquista da terceira Copa do Mundo em 1970 no México, quando vigorou o mote: "Brasil, ame-o ou deixe-o", que veio a exercer alta influência nas bolsas de valores brasileiras iniciada ao final da década de 1960 e resultou em um clima de euforia generalizada - incentivado por canções como Pra frente Brasil -, apelidado pelo autor de vários livros sobre este período, Elio Gaspari (2002) de "patriotada". Segundo Reinaldo Gonçalves (2002), professor da UERJ e economista, o período do milagre econômico foi o que gerou maior crescimento do país desde a Proclamação da República. A proposta do ministro do Planejamento, Delfim Neto, consistia em concentrar a renda, formando um "bolo econômico", a ser posteriormente dividido.

Em 1973 ocorreu a crise mundial do petróleo, que para o Brasil trouxe como conseqüência arrocho salarial, o desemprego, a recessão, o endividamento externo, o inchaço da maquina publica, a desnacionalização da economia e desperdício de recursos públicos.

Neste contexto inicia-se em Balneário Camboriú o governo municipal de Gilberto Américo Meirinho (iniciado em 1973 foi até 1977). A cidade contava com uma população de pouco mais de 10 mil habitantes ${ }^{7}$, segundo documentos do Arquivo Histórico da Cidade, e uma estrutura fundiária irregular, baseada nos assentamentos que se instalavam, nem sempre com respaldo legal no uso destas ocupações.

O prefeito recém-empossado contratou a empresa paranaense Planepar (Planepar- Organização de Planejamento Técnico e Econômico) de Curitiba, com o intuito de dar continuidade ao Plano Urbano para a cidade de Balneário Camboriú, cujo estudo feito na gestão do Prefeito Higino Pio já delineava o sistema viário e a numeração das ruas da cidade. (MEMORIAL, 2014).

Contando com uma grande equipe multidisciplinar, a empresa produziu um diagnóstico científico da realidade física, social, econômica, política e administrativa da cidade, apresentando então, um conjunto de propostas para o desenvolvimento do município: cadastro técnico municipal, o projeto executivo do sistema de abastecimento de água, o projeto dos esgotos sanitários e o plano diretor do município do Balneário Camboriú, que seria o norte de todas as ações concretas de intervenção sobre o território, pelo setor público ou por qualquer outro agente.

7 Fonte: de acordo com dados fornecidos pelo Arquivo Histórico, Balneário Camboriú em 1970 contava com 10.180 habitantes. 
Todo o trabalho foi orientado pelo prefeito e seus assessores diretos, sem participação dos moradores locais ou de seus representantes eleitos da câmara de vereadores, tal como comenta o Engenheiro Jorge Otávio Cachel, em entrevista aos autores desta pesquisa (informação verbal) ${ }^{8}$. Com tais características tecnocráticas e um discurso positivista, o projeto urbano veio com inspiração no modelo de Curitiba $\mathrm{PR}$, com alguns princípios do urbanismo modernista, na divisão da cidade em zonas funcionais, a transformação de ruas em avenidas, a hierarquização do sistema viário em dois eixos principais (longitudinal e transversal) e a identificação das necessidades segundo um critério técnico, porém sempre amparado no conceito de "cidade para as pessoas", conforme a fala do prefeito Gilberto Meirinho em entrevista para Paulo Leme (LEME, p.212). Na ilustração abaixo vemos o traçado do sistema viário proposto, inspirado no modelo modernista de Brasília.

\section{ILUSTRAÇÃo 1. Croquis do Plano Urbano.}

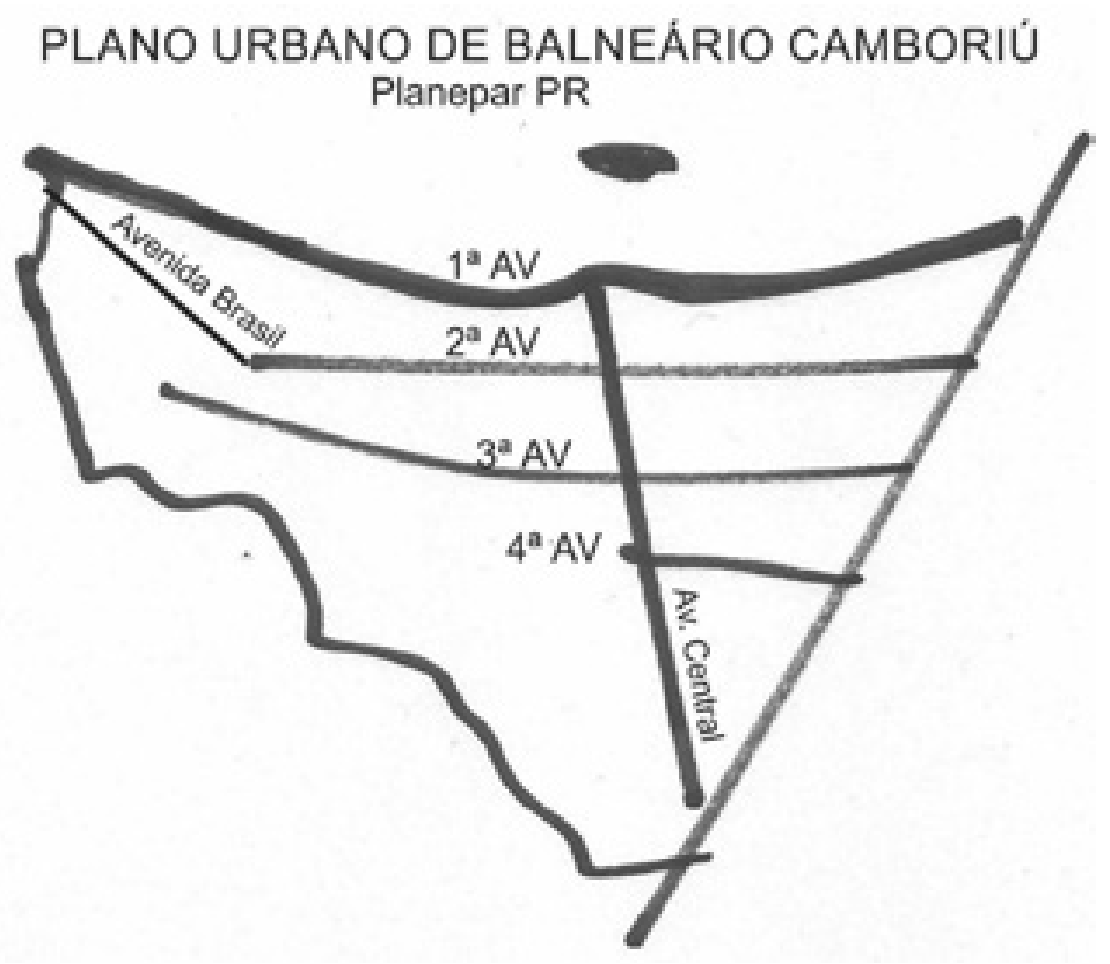

Fonte: Memorial Prefeito Meirinho.

8 Informação obtida do Engenheiro Otávio Cachel, secretário municipal de obras em 1974, em entrevista realizada em 25 de janeiro de 2014. 
O critério adotado foi a escala humana, as avenidas não muito largas e com canteiro central, calçadas amplas (para os padrões da época) inclusive na beira-mar.

O passeio público da Avenida Atlântica foi determinado por decreto (Decreto no 707 de 17 de fevereiro de 1974. $)^{9}$ quando foi declarado de utilidade pública para fins de desapropriação na faixa de terras de marinha com a largura de seis metros em toda a extensão da Avenida. Não obstante o Código de Normas e Instalações, criado pela Planepar, prever calçadas largas na orla, muitas residências possuíam muros demarcando a propriedade até a faixa de areia. O prefeito Meirinho ordenou a derrubada destes muros, originando um embate judicial e dividindo a população entre os que viam na medida "uma arbitrariedade descabida" e os que percebiam no episódio uma “modernização da cidade, com a avenida e calçadão” (LEME, 2010).

O Tribunal de Justiça do Estado de Santa Catarina deu ganho de causa para os reclamantes, permitindo que os ocupantes das terras de Marinha reconstruíssem os muros fora do alinhamento previsto pelo Código de Posturas da prefeitura, não levando em conta que as terras de frente para o mar são por lei, da Marinha do Brasil, conforme o artigo 180 da Constituição (JUSBRASIL, 2014).

O referido artigo ofereceu embasamento ao projeto, pois o texto determina que, a 33 metros da preamar média seguindo o mapa de 1831, todas as terras serão de propriedade da Marinha, e geridas pelo Serviço do Patrimônio da União. Este instrumento da lei permitiu que o prefeito, com o apoio da Marinha (CPSC - Capitania dos Portos de Santa Catarina), decretasse o suporte legal do calçadão, que foi sancionado pelo poder público local.

\section{A PRAÇA ALMIRANTE TAMANDARÉ}

A lei no 104 de 15 de julho de 1969 criava um espaço desapropriado onde hoje está a praça pública, sendo posteriormente criada uma lei, de no 113 em 29 de agosto de 1969, para denomina-la oficialmente como Praça Almirante Tamandaré, nome do patrono da Marinha do Brasil, título de Joaquim Marques Lisboa, tido como personagem heroico em guerras do Brasil Imperial. No entanto este espaço público não havia recebido nenhum tratamento ou projeto de apropriação real. Nem sequer havia uma área demarcada neste local, dando margem a ocupações indevidas.

O escritor Paulo Leme (2010) descreve no seu livro "O Semeador" a trajetória da urbanização da cidade neste período, com depoimentos dos atores envolvidos,

9 Fonte: Arquivo Memorial Prefeito Gilberto Américo Meirinho. 
notadamente os agentes do setor público municipal. Com base neste relatos, nos documentos dos arquivos do Memorial Prefeito Meirinho, entrevistas com o secretário de obras, com o diretor administrativo e com funcionários do município deste período histórico, tomam-se como subsídios para este construto que, se não pode despir-se totalmente do filtro dos valores próprios dos autores, impõe-se um certo rigor metodológico para imprimir veracidade na pesquisa.

A questão das propriedades muradas até a faixa de areia da praia central de Balneário Camboriú não foi o único obstáculo encontrado pelo poder público, quando da execução da obra da Avenida Atlântica. No curso da nova avenida havia um tapume de obras, fechando uma área que, segundo os supostos proprietários, era privativa e um projeto aprovado permitia que ali se construísse um edifício. O prefeito, afirmando a não existência desta autorização, ordenou a derrubada do tapume e retirada de todo o material e pessoal do local, permanecendo ali, onde está até os dias de hoje, estacas do edifício iniciado. Determinou então que se contornasse a área, assim a avenida teria um desvio, mas não iria ser obstruída por um processo moroso na justiça. Com esta atitude, anexou-se esta área em litígio à orla, impedindo definitivamente qualquer edificação que não fosse pública. A reação foi imediata, com a prisão do calceteiro Candido, que trabalhava no calçamento da via pública, com o pedido de impugnação do mandato (impeachment) do prefeito e ordem de prisão para o secretário de obras. Novamente a interferência da Capitania dos Portos foi decisiva na solução sui generis da cidade, apoiando o prefeito, expedindo documentos defendendo como legítima a ação da prefeitura municipa ${ }^{10}$.

Em contrapartida a praça recebeu o nome do patrono da Marinha, com busto do homenageado, provocando indignação na população local, cujo primeiro prefeito eleito havia sido executado há pouco tempo (03/03/1969) na Capitania dos Portos da Marinha (CNV, 2014).

O exercício do poder, propiciado pela ditadura militar foi preponderante na história da praça. Assim como a imposição dos projetos desenvolvidos no gabinete do prefeito, todos os empenhos foram feitos no sentido de consolidar o balneário como destino turístico. $\mathrm{O}$ design dos espaços públicos foi submetido à esta orientação política.

Nestes quarenta anos de existência a Praça Tamandaré passou por três grandes transformações. Sua trajetória histórica do ponto de vista funcional transcorreu

10 Boletins da Capitania dos Portos estão na íntegra no Arquivo Histórico de balneário Camboriú. Dia 23 de fevereiro de 1974, o boletim no3 com o título "MARINHA ALERTA", A Capitania dos Portos de Santa Catarina alertava sobre o uso das terras sobre posse da Marinha do Brasil e a possível demolição de edificações irregulares, baseado no decreto federal no 50.114 de 26 de janeiro de 1961. 
com mudanças no uso e na apropriação de seu papel no contexto urbano. $O$ conceito inicialmente era de um espaço destinado para eventos, onde foi instalada uma grande estrutura metálica de treliças espaciais e cobertura de policarbonato.

Havia então a intenção de propiciar apresentações públicas em uma área protegida e privilegiada pela localização na orla marítima da cidade. Em alguns momentos o espaço público foi visto também como um campo propício para divulgação de atividades de empresas privadas. Durante os anos 1985 até 1987 a cobertura da praça ostentava a logomarca da empresa construtora H. Schultz, de propriedade do prefeito neste período, em uma das atitudes usurpadoras do poder instituído se apropriando do espaço público. Na ilustração abaixo se pode ver a Praça Tamandaré com a cobertura e logomarca.

Figura 2. Praça Almirante Tamandaré 1983

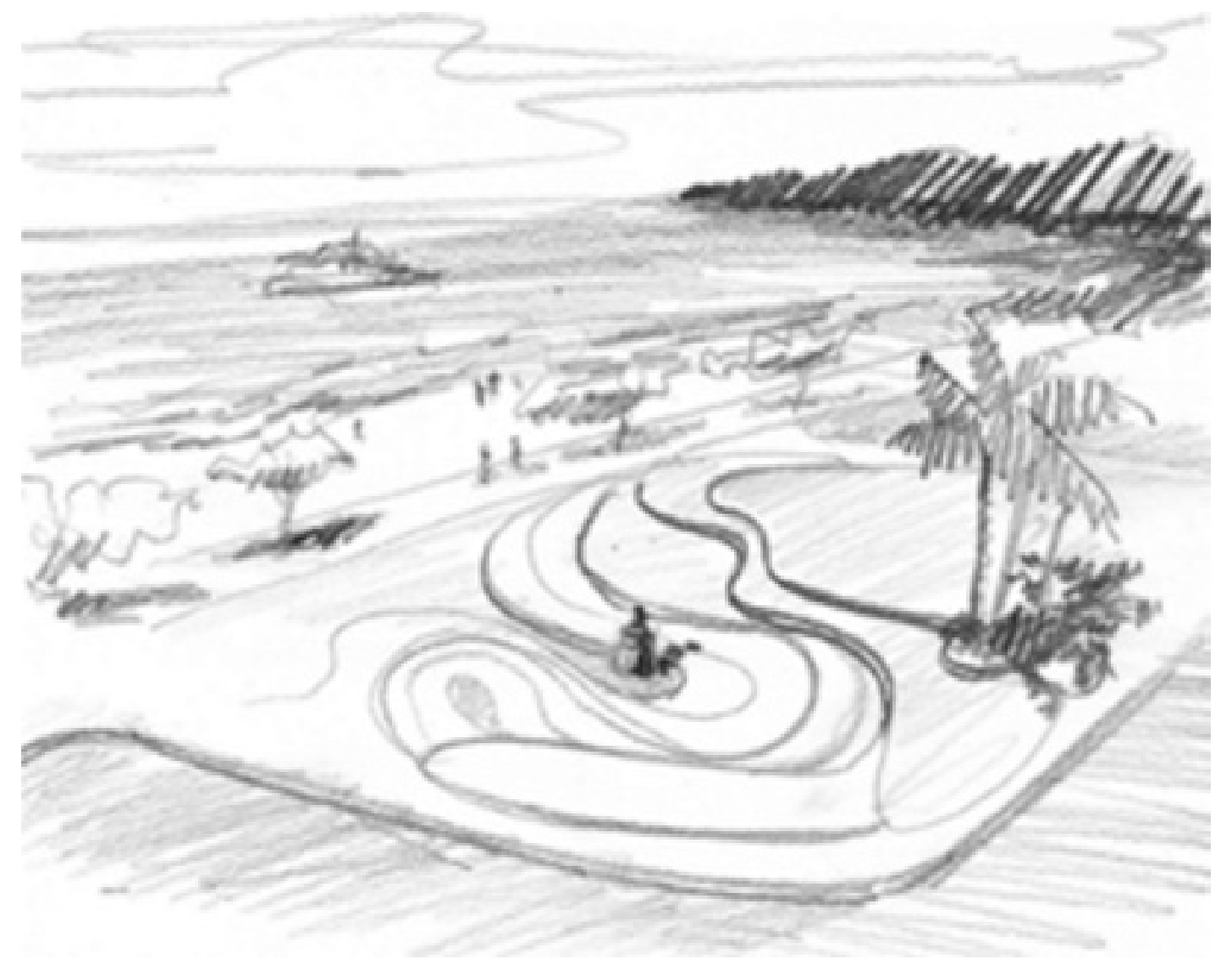

Fonte: Croquis do autor

Posteriormente a praça ganhou um novo conceito, como o desenho de um palco, 
com vários níveis construídos em degraus, que favoreceriam as apresentações, com espaço para o público assistir. A política urbana estaria fundamentada na demanda turística e em propiciar atrações para esta demanda.

Figura 3. Praça Almirante Tamandaré 1990

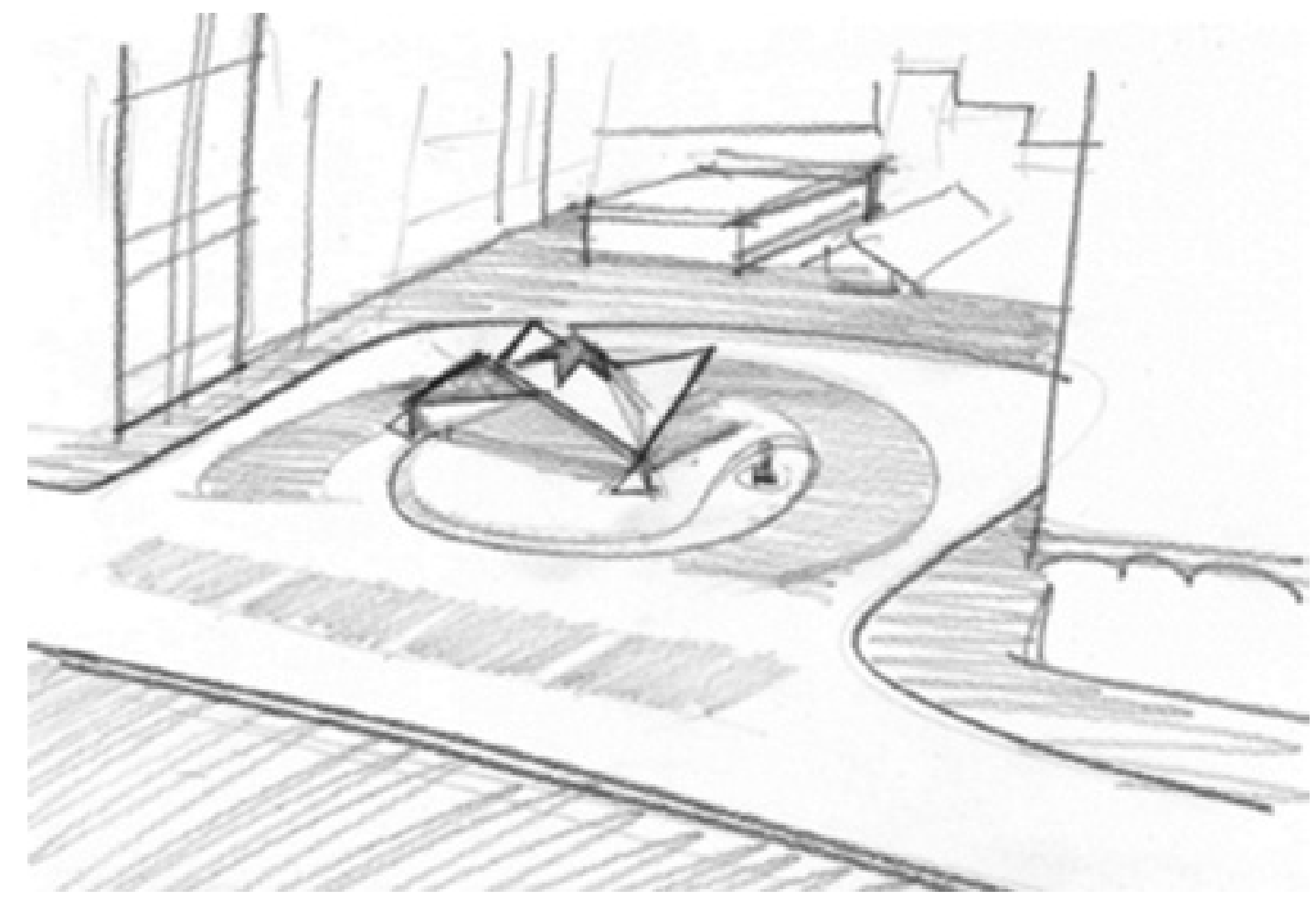

Fonte: Croquis do autor

Com relação ao aspecto da representação simbólica, a praça está temporalmente delimitada pelo significado que a história Ihe concedeu. Sem projeto que Ihe definisse a identidade, sem acessibilidade por sua localização incômoda, entre o fluxo intenso e o limite das barreiras físicas construídas, sem legibilidade na sua indecifrável concepção fragmentada em planos, para usar uma breve análise baseado nas três dimensões fundamentais descritas por autores contemporâneos, como Lucio Ginnover (2006, p.30). 


\section{Figura 4. Praça Almirante Tamandaré 2013}

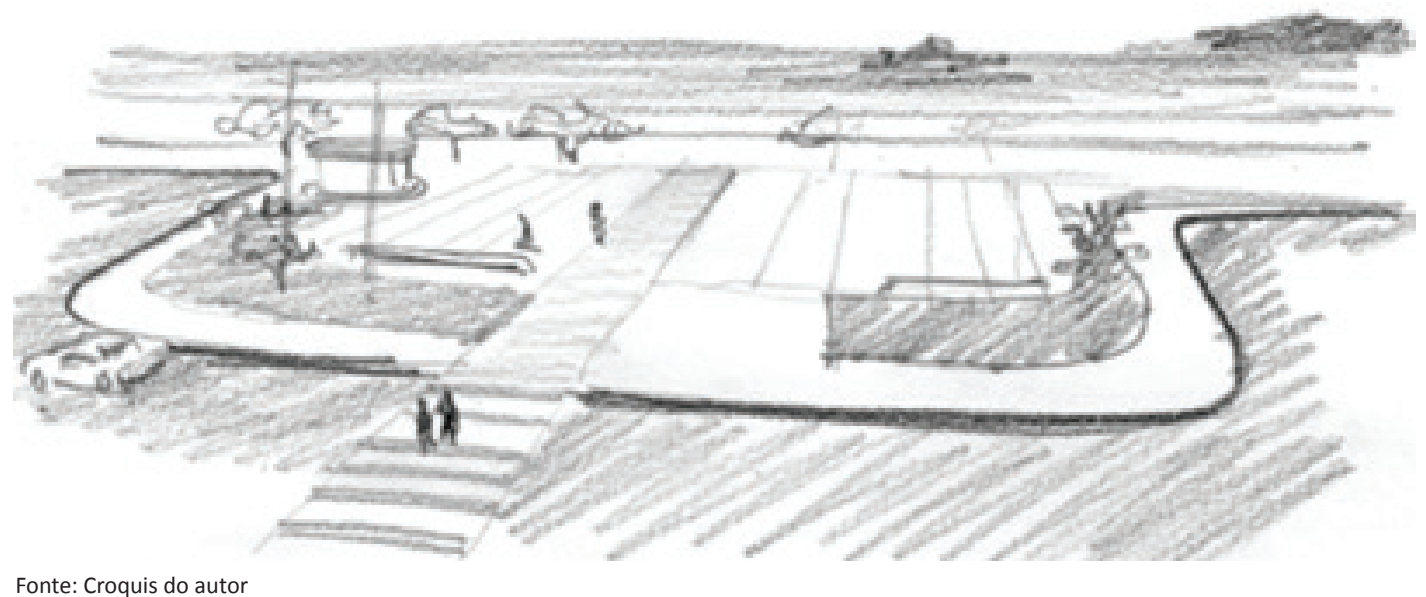

Na última revisão estética e funcional em 2013, adotou-se o espaço cívico como conceito, o espaço vazio, livre para eventos, porém com ênfase na circulação e lazer passivo. O conceito de espaço livre desenvolve-se como ordenamento espacial produzindo a dissolução da praça tradicional, como menciona Junia Caldeira (2007, p.8). A questão formal é predominante, pois existe um grafismo que se observa apenas do alto, orientando o fluxo.

Na fala do ex-diretor da Secretaria do Estado para o Turismo, SANTUR, e ex-secretário municipal de turismo, Osmar Nunes Filho11: -"As gestões municipais priorizaram sempre a captação de volume de turistas". A quantidade de pessoas na praia era motivo de comemorações. O turismo de massa, ou turismo de sol e praia, de baixo custo, passou a ser a característica do local. Com esta política a cidade definiu toda sua vida econômica em função do desenvolvimento turístico, organizando-se para produzir paisagens atrativas para o consumo e para o lazer. O espaço público passou a ser utilizado como atração turística apenas.

\section{CONSIDERAÇÕES FINAIS}

O espaço escolhido para a pesquisa está no centro geográfico e geométrico da praia central de Balneário Camboriú. Configurando-se, portanto como uma área rara e cara, circundada de edifícios de alto luxo, em um balneário prestigiado pelo turismo nacional e estrangeiro.

11 Entrevista concedida em 11/02/2013 
O presente trabalho procurou entender a relação da hospitalidade e o design de seus espaços públicos, utilizando a trajetória deste, especial para a cidade, e a implicação que poderia ter na atividade turística local.

No discurso dos moradores encontrou-se a critica aos projetos destes ambientes como não identificados com a população local. Como o discurso é algo construído social e historicamente, o entendimento exige obrigatoriamente uma análise do passado da cidade. Tratou-se de buscar na linha do tempo os dispositivos que supostamente teriam conduzido à construção da cidade de forma alheia aos desejos dos moradores.

A história desta praça, iniciando com o primeiro plano diretor da cidade até a atualidade, mostra um contexto de grandes equívocos, desde o aspecto ambiental, com o ambiente modificado em função do crescimento rápido e que prestigia empreendimentos da construção civil, desconsiderando questões importantes, como a sustentabilidade no lugar. Equivocado também, o caráter ideológico, com a inspiração modernista na concepção urbana contida no projeto de 1974: a praça com grande dimensão morfológica, mas transformada em espaço vazio, desarticulado do cotidiano, sendo utilizada apenas para eventos da atividade turística.

De forma transversa, também o nome da praça que homenageia o patrono da Marinha, assim como o monumento do Almirante, se configuram como uma imposição para o reconhecimento do espaço como praça pública.

Apesar da praça ter surgido como uma "salvaguarda" contra a voracidade dos que tomavam para si partes públicas do território, o destino dado à esta porção pouco contribuiu para a apropriação dos moradores locais. Pouco se investiu nestes espaços para torna-los lugares com acessibilidade, fornecem pouca legibilidade, por possuírem signos pouco definidos. Tampouco se percebe identidades próprias: análise das práticas e representações presentes nos espaços leva a perceber que o sentimento de pertencimento ao local ainda não tem respostas como identidade própria ou apropriada.

Porém, cabem ainda novos estudos que aprofundem a questão centrada nos territórios e nas suas especificidades, onde se destaca o património e os valores patrimoniais. Outros espaços públicos de praças na área urbana possuem características totalmente diversas destas aqui pesquisadas.

A valorização e promoção destes espaços, tornando-os acessíveis, legíveis e identificados, atendendo adequadamente a população local, pode ser um modo de galgar níveis de qualidade na atividade turística, dispondo de lugares com condições excelentes para receber turistas. 
O que se pesquisou até a presente data (2014) em entrevistas abertas aos moradores ${ }^{12}$, leva a crer que os projetos urbanos desenvolvidos pelo poder público local não estão em sintonia com a opinião da coletividade e os canais de comunicação com os gestores não estão funcionando.

A via democrática é a mais penosa e demorada, mas é a única verdadeira, nas palavras de Klaus Frey (2001), apontando para um equívoco comum das cidades turísticas: não considerar os desejos da população local, privilegiando as iniciativas para a demanda turística. A hospitalidade não pode se sustentar com "atrações construídas", se a população não aprovar os projetos.

Este artigo buscou resgatar a história da praça e estudar a relação entre a hospitalidade pública e o design urbano que se evidencia na história deste espaço público. Porém é uma perspectiva parcial de um cenário muito amplo dos espaços públicos urbanos valiosíssimos, cujos projetos deveriam estar alinhados com os interesses da população local. Sugere-se que este estudo seja estendido para outros espaços públicos da cidade.

\section{REFERÊNCIAS BIBLIOGRÁFICAS}

BOULLÓN, Roberto. Planejamento do espaço turístico. Bauru: EDUSC, 2002.

CALDEIRA, Junia. A Praça Brasileira. Trajetória de um espaço urbano: origem e modernidade. Tese de doutorado - Universidade Estadual de Campinas, 2007.

CAMARGO, Luiz O. L. A pesquisa em hospitalidade. Intercon - Sociedade Brasileira de Estudos Interdisciplinares da Comunicação. Santos: XXX Congresso Brasileiro de Ciências de Comunicação, 2007

CNV. Comissão Nacional da Verdade. Laudo da morte do prefeito. Disponível em: http://www.cnv.org.br acesso em: 29/02/2014.

D’ARAUJO, Maria Celina Soares et al. (Ed.). Os anos de chumbo: a memória militar sobre a repressão. Relume Dumará, 1994.

FREY, Klaus. A dimensão político-democrática nas teorias de desenvolvimento sustentável e suas implicações para a gestão local. Ambiente \& Sociedade, v. 9, n. 1, p. 115-148, 2001.

12 As entrevistas realizadas para a pesquisa de dissertação de mestrado de Turismo e Hotelaria serão apresentadas no Trabalho "Hospitalidade Urbana e Design de Espaços Públicos Urbanos: a trajetória das praças públicas na área central de Balneário Camboriú SC/Brasil" realizado pelos autores. 
GASPARI, Elio. A ditadura envergonhada. São Paulo: Companhia das Letras, 2002. GONÇALVES, Reinaldo. Globalização e desnacionalização. Paz e Terra, 1999. GRINOVER, Lucio. A hospitalidade urbana: acessibilidade, legibilidade e identidade. Revista Hospitalidade, São Paulo, ano III, n.2, p. 29-50, 2. Sem. 2006.

JUSBRASIL. www.jusbrasil.com.br JUSBRASIL> www.jusbrasil.com.br/topicos/.../ artigo-180-da-constituicao-federal-de-1937. Acesso em: 13/03/2014.

LEFEVRE, Fernando; LEFEVRE, Ana Maria Cavalcanti. O discurso do sujeito coletivo: um novo enfoque em pesquisa qualitativa (desdobramento) Caxias do Sul: EDUCS, 2003.

LEME, Paulo. O semeador - vida e obra de um semeador. Balneário Camboriú: Editora Taqui, 2010.

MEMORIAL PREFEITO MEIRINHO. Arquivo de documentos da gestão pública municipal. Balneário Camboriú, 2014

NERY, Raquel da Costa. Urbanismo Moderno. IPHAN, 2013.

PND. Plano Nacional de Desenvolvimento 1973. www.Planalto.gov.br. Acesso em 03/10/2014.

ROBBA, Fabio; MACEDO, Silvio Soares. Praças brasileiras: Public Squares in Brasil. São Paulo: Edusp, 2010.

ROLNIK, Raquel. Anais: Seminário de história da cidade e do urbanismo. São Paulo: vol. 2 Ed. 1 p. 27-29. 2012.

ROSSI, Aldo. A arquitetura da cidade. São Paulo: Martin Fontes, 2001.

SÁNCHEZ, Fernanda. A reinvenção das cidades. Chapecó: Argos, 2002.

SINGER, Paul Israel. O" milagre brasileiro": causas e consequências. CEBRAP, 1972. 